and 3,980 were then selected. All these people showed no pathological changes at the time the blood was taken, had never suffered from liver diseases or jaundice, and did not habitually consume large quantities of alcohol. This group was regarded as "clinically fairly healthy." The distribution of the transaminase levels corresponded to a $\log$ normal curve. It was shown that for the establishment of the normal range limit sex, age, weight, and size needed consideration. The range of normal values we derived from this investigation were given as orientation values for persons of normal weight, normal size, and medium age. We differentiate only between the sexes.

The population examined by Professor Baron and colleagues is obviously different from that of Laudahn et al. According to the tables given by Laudahn, these persons must have been, on average, younger or of smaller size and/or of lower weight. Furthermore, the techniques and measurement employed by Professor Baron and colleagues and Laudahn et al. were different. Both of them used Boehringer Mannheim optimized reagent packs which follow the recommendation of the German Society of Clinical Chemistry. ${ }^{2}$ The Laudahn group performed their assays at $25^{\circ} \mathrm{C}$. In contrast the Baron group worked at $35^{\circ} \mathrm{C}$ and reduced their values by mathematical conversion to $25^{\circ} \mathrm{C}$. Unfortunately they did not give their conversion factors. The conversion of measured results, determined at different temperațures, is always problematic. The problem is particularly severe as soon as isoenzymes with different factors for temperature conversion occur in the serum.

We feel that before any statement of normal values can be generally accepted the values of several laboratories should be considered. It would be useful to determine the range of normal values for temperatures commonly used for the determinations, and any laboratory publishing its results should give exact details on the population examined. We would like to hear more from Baron et al. on the normal values valid at $35^{\circ} \mathrm{C}$, and details on the population taken. Conversion factors for different temperatures should-if at all-be permitted only, if many determinations on a large number of normal and pathological sera have been performed at the same time at different temperatures. In this way not only the conversion factor but also the variation coefficient for this factor can be given. The conversion factors should be used only, if such examinations prove that the variation coefficient is small compared with the variation of the method.-We are, etc.,

W. GRUBER H. U. BERGMEYER Boehringer Mannheim GMBH, Bochemica Werk, Tutzine, 1 Laudahn, G., Hartmann, E., Rosenfeld, E. M.,
Weyer, H., and Muth, H. W., Klinische
Wochenschrift, 1970, 48, 838. Wochenschrift, 1970, 48, 838.
2 Ceitschrift für klinische Chemie und klinische
Biochemie, 1970, 8, 658.

\section{V.D. Statistics}

SIR,-Dr. L. Watt (4 December, p. 623) is right to draw attention to the difference between the number of persons attending and the number of registrations recorded in venereal disease clinics, but he is wrong to impugn me. If he should re-read my article
(6 November, p. 342), to which he refers he will find my words chosen with forethought, for I referred to cases of this and that, to patients (including "repeaters"), and registrations (not all have infections) each in the correct context.

In Newcastle we are well aware of dual diagnoses, and have kept detailed statistics such as the Department of Health now call for since 1964, so we have little to learn as Dr. Watt's letter suggests to the contrary, nor are we guilty of "ovenereologistics" (my word for cooking the V.D. books).

Dr. Watt suggests that exaggeration serves no useful purpose. In 1970, the number of persons attending the clinic at Newcastle was 3,531 and the number of registrations, including those seeking reassurance only, was 3,778 . On this basis, the national registration figure of 250,000 represents a total of 232,500 persons registered at clinics in England and Wales in one year. The exaggeration amounts to $7 \%$ and in my opinion causes less harm than befogging the issue each time with a resumé of statistical and accountancy methods.

I said in my article "drawing lurid pictures and quoting dire consequences should have no part in educating the public in V.D. today." I agree with Dr. Watt that we must disseminate knowledge rather than fear and I for one do not subscribe to the view that there are "12 venereal diseases." On the other hand, the public must be appraised of the situation statistically, and if we acquaint it of an approaching epidemic we imply that V.D. is to be avoided if possible-that is, is to be feared. If not, what is the fuss? I go further and insist that sexual promiscuity, quite apart from its sequalae of pregnancy and disease, is sordid and not conducive to ultimate happiness. Education must extend to include awareness of wholesome human relationships. It is absence of this which results in venereal disease so besetting the country today.-I am, etc.,

Newcastle General Hospital,

Newcastle upon Tyne

A. S. WIGFIELD

\section{Hospital-based Social Workers}

SIR,-I would like to support every point raised by Drs. J. A. Harrington and P. A. Barker (27 November, p. 562).

For the first time since we have opened this rehabilitation unit 16 years ago we are having great difficulty in recruiting suitable social workers as valued members of our rehabilitation team. They not only look after the interests of the patients, who may come from Devon, Lincoln, or Cumberland, but also discuss the management of the patients' social problems with the other members of the staff. The service a good social worker can give a patient at this stage, in helping him and his relatives to accept disability in a constructive way, is far beyond that of an interest in a local resettlement.

Just when we are severely short of social workers we have never had so many requests from various colleges to train students in the medical social field. If hospitals are denuded of social workers, other members of the team working full time will have to take over this work. Surely this would be a retrograde step? -I am, etc., Rivermead Hospital,
Oxford

Celia Westropp

\section{Typhoid Carriers}

SIR,-In the leading article on Typhoid Carriers (27 November, p. 507) it was surprising to read ampicillin being described as "so effective in clinically active infection" of typhoid fever.

I have recently reviewed antibiotic therapy in 75 cases of acute typhoid fever admitted to the infectious diseases department of the Royal Free Hospital at Coppetts Wood Hospital, from 1959 to 1969. Sixteen patients received ampicillin, $4 \mathrm{~g} / 24 \mathrm{hr}$, intramuscularly for 14 days. None of these patients showed a satisfactory and effective response comparable to chloramphenicol, though ampicillin serum levels in some patients were well above the minimum inhibitory concentration needed, as shown in the Table.

Ampicillin Serum Concentraton $(\mu \mathrm{g} / \mathrm{ml})$ in Four Patients after $1 \mathrm{~g}$ Ampicillin Given Intramuscularly after taking the 2 p.m. Blood Sample. Patients were Receiving Ampicillin $1 \mathrm{~g}$ Sample. Patients were Re
Intramuscularly 6-hourly.

\begin{tabular}{c|c|c}
\hline Patient & Time & $\begin{array}{c}\text { Serum concentration } \\
\mu \mathrm{g} / \mathrm{ml}\end{array}$ \\
\hline 1 & 2.00 p.m. & 17.0 \\
2 & 3.15 p.m. & 35.0 \\
3 & 2.00 p.m. & 15.0 \\
4 & 2.00 p.m. & 27.0 \\
4.00 p.m. & 92.5 \\
& 2.00 p.m. & 4.7 \\
& 3.00 p.m. & 32.0
\end{tabular}

Ampicillin appears to be inferior to chloramphenicol in the treatment of acute typhoid fever. This view is supported by Sanders ${ }^{1}$ and Patel. ${ }^{2}$ Even its role in the eradication of chronic typhoid carriers is also debatable.-I am, etc.,

S. HAIDER

Royal Free Hospital,

Infectious Diseases Department,

Coppetts Wood Hospital,

1 Sanders, $W$. L., British Medical fournal, 1965, 2, 1226.
Patel, K. M., British Medical fournal, 1964, 1,
907.

\section{Chapels of Rest}

SIR,-The conditions of "chapels of rest" (27 November, p. 562) should have the attention of local authorities and others so that such premises can be made to conform to the necessary statutory requirements still to be determined. "Chapels of Rest" would be a suitable subject for consideration by the Society of Medical Officers of Health or the Royal College of General Practitioners, who could make recommendations to the appropriate quarters.

Accredited establishments of this kind would have repositories with refrigeration and chapel facilities similar to those of area hospital mortuaries. Among many other things this would obviate the need (and charges made) for the sanitation procedures (modified embalming) increasingly practised even when cremation takes place some 3648 hours later.

Such legislation and enforcement are necessary and should operate until such matters as removal, respectful safe-keeping, and later cremation become accepted and provided as a wholly State service-“the last Offices" of community health.-I am, etc.,

North Middlesex Hospital,
London N.18

J. F. HEGGIE 